\title{
Development of a Three-dimensional Computer Graphics System for Forest Stand Structures
}

\author{
Yoshihiro Nobori*1
}

\begin{abstract}
There have been a number of reports on the three-dimensional analysis of forest stand structures using personal computers. In recent years, it has become easy to display 3D graphics on Microsoft's Windows 95 operating system. Forest Window (FW) has been developed as a new 3D-simulation program for forest stands. This report provides an overview of $\mathrm{FW}$ and explains its operation. One of its features is its ability to show stem inclination. The object of this report is to appraise the usefulness of FW. As the result of the study it was recognised that we can use a simpler data structure and FW can display more complicated forest structures than in past applications. FW is a useful application and, run in conjunction with spreadsheet software, it can provide an effective way of studying forest stand structures.
\end{abstract}

Keyword : forest stand characteristics, three-dimensional structure, personal computer, simulation, application program

\section{INTRODUCTION}

There have been several reports in past years on the 3D analysis of forest stand structure. TANAKA (1944) and Mitchell (1975) made models of tree stem and crowns based on research data. After the appearance of computers, Nobori (1990) reported a simplified three-dimensional computer graphics system. Features of the 3D methods used in that system were that the trees were described in order from most distant to nearest and the tree forms were described by symmetric rotation. But tree data could not be sorted in the application software. In the early 1990s, personal computers became widely available and the applications were adapted for such computer systems. Nobori demonstrated the use of such 3D systems with an analysis of a mixed forest structure in central Hokkaido (NOBORI 1991) and reconstruction of a tertiary fossil forest structure from the Canadian high Arctic (NoBori 1997).

Recently, universal operating systems for personal computers have come into use, making it easy to develop software for widespread public use. This paper reports on the development of a new 3D system for forest stand

${ }^{* 1}$ Department of Biological Environment Science, Yamagata University, 1-23 Wakabamachi, Tsuruoka, Yamagata, 997-8555, Japan structures named Forest Window (FW).

\section{D SYSTEM COMPOSITION}

The 3D system that explained in this report comprises a personal computer, operating system, 3D-image software, forest information database and Microsoft Excel

(Microsoft 1997) or compatible spreadsheet software. FW was developed on an NEC PC-9821 personal computer with the Microsoft Windows 95 operating system. The programming language used was Fujitsu F-Basic97 (FujIT. su 1997a, 1997b). An executable file is created after compilation by F-Basic97. FW also requires some dynamic link library files for user interfaces, and a quick sort library is needed to draw trees on the computer display. These libraries, which were supplied by Fujitsu, should be put in the same directory as FW or the system directory for Windows 95.

FW can run under Microsoft Windows NT or Windows 95 operating systems installed on IBM-compatible personal computers. It can also run on Apple Macintosh computers installed with a Windows 95 emulation system. FW is supplied on one 3.5 inch floppy disk containing the following 6 files: FW.EXE, the main program of FW; SAMPLE.CSV, sample data of forest stand structure; README.DOC, text of instruction manual; F1A0QSRT. DLL, quick sort library; F1A0RN50.DLL, dynamic link 


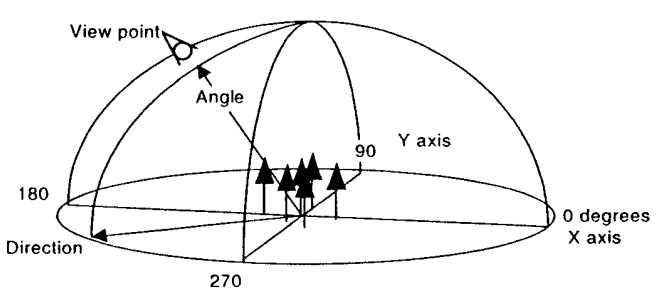

Fig.1 The relationship between viewpoints and axes of coordinates

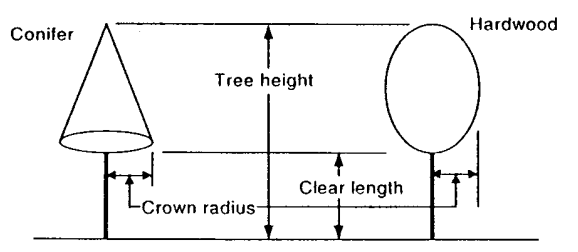

Simplified tree forms of perpendicular stem

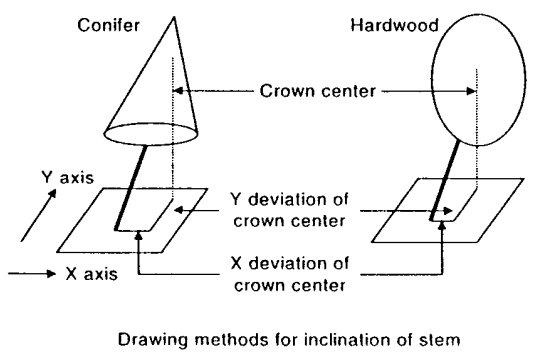

Fig.2 Tree form and requisite data

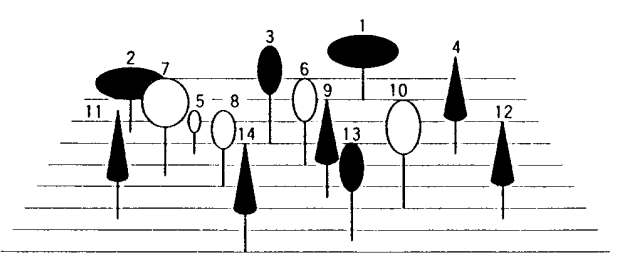

Fig.3 Simplified 3D method in FW

Note: Drawing trees in turns from distant to near library for basic instructions; and F1A0RW50.DLL. dynamic link library for more advanced instructions.

FW can read only CSV format (comma-separated variables) data of forest stand structure. The data fields and their meanings are shown in Table 1.

FW can draw up to 1000 trees. There are advanced spreadsheet programs available that can be used to edit the $\mathrm{CSV}$-format data used in FW. The relationship between angle and axis of coordinates are that the horizontal level is 0 degrees and the vertical is 90 degrees. The relation between the axes of coordinates and viewpoints is shown in Fig. 1.

\section{SIMPLIFIED 3D METHODS IN FW}

Various methods of three-dimensional computer graphics were considered. The ordinary method has parallel movement, three-dimensional axis rotation, projection transformation and transformation of the coordinates system to the computer screen. To overcome some problems found with this method, a simplified model of threedimensional computer graphics was adopted for this study. The observation point was set as the centre of the computer display. Conifers are described by conical shapes and hardwoods are described by elliptical sphere shapes (Fig. 2). FW can display tree forms with straight inclined stems but not bent stems. When the trees are viewed from a high angle (or vertical), every crown should appear as a circle. In this case, it would not be possible to distinguish between conifers and hardwoods. Hence FW shows a half-circle shape for conifers at a high-angle viewpoint.

The trees are described in order from distant to near (Fig. 3). The three-dimensional computer graphics can be summarised as follows. The transformation of the 3D coordinates system to the computer screen is necessary only on the basis of two-dimensional axis rotations. There was no need for view transformation. The transformation

Table 1 Forest information data structure

\begin{tabular}{ccccc}
\hline Field code & Meaning & Unit & Format & Remarks \\
\hline XA & X axis of tree direction & Meter & Real & \\
YA & Y axis of tree direction & Meter & Real & \\
ZA & Z axis of tree direction & Meter & Real & \\
SP & Species & String & & 10 characters \\
NL & Conifer or hard wood & String & & 1 characters \\
HI & Tree height & Meter & Real & \\
BL & Clear length & Meter & Real & \\
DB & Diameter at breast height & Centimetre & Real & \\
CR & Radius of tree crown & Meter & Real & \\
CX & X deviation of crown centre & Meter & Real & \\
CY & Y deviation of crown centre & Meter & Real & $0-15$ \\
CC & Color code & & Integer & \\
\hline
\end{tabular}




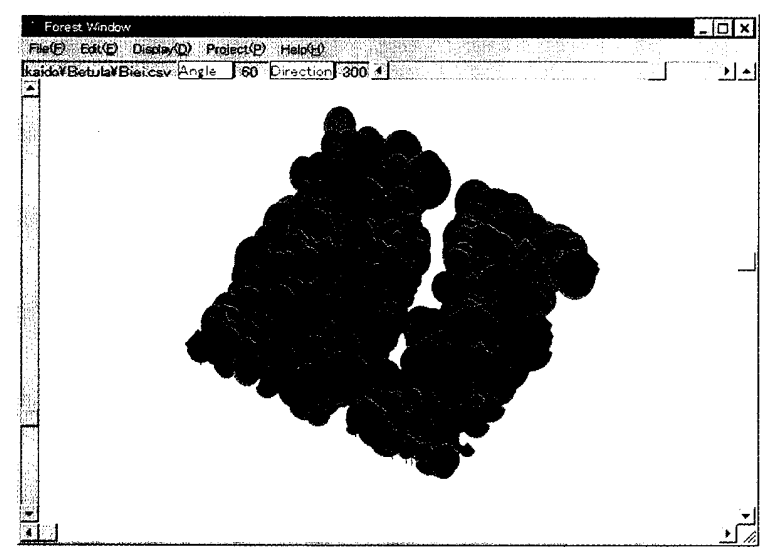

Fig.4 Display image of mixed forest structure in Hokkaido

Note: Observation point is at a direction of 300 degrees and an angle of 60 degrees.

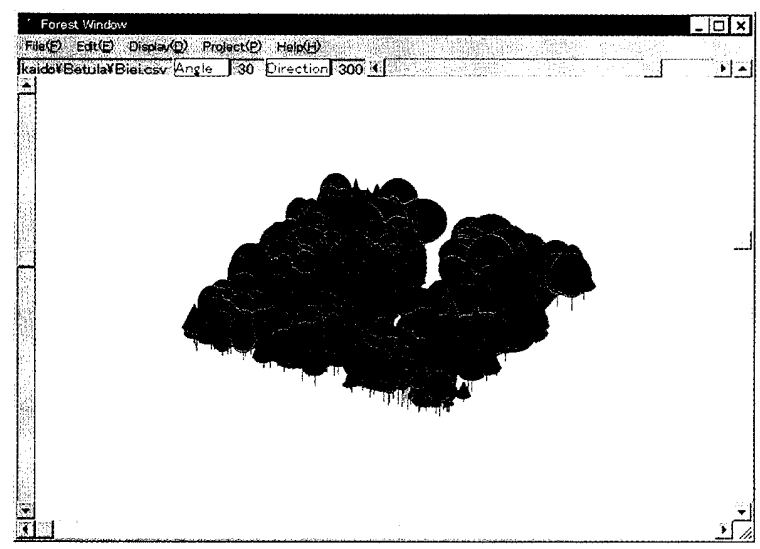

Fig.5 The same forest structure from an angle of 30 degrees

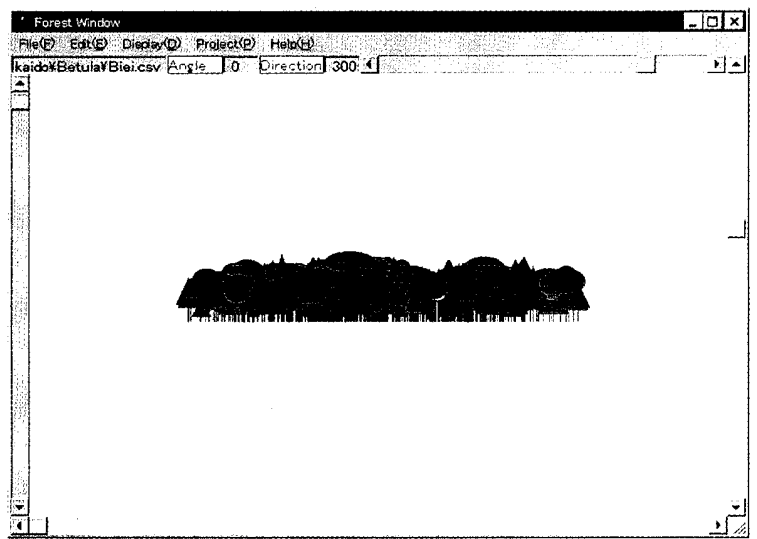

Fig.6 The same forest structure from horizontal viewpoint of single tree form was necessary only on the basis of one-dimensional axis rotation. But this method has some limitations. One of them is that it is difficult to observe from a viewpoint just above the trees. FW therefore restricts the viewing angle to under 80 degrees.

\section{OPERATION OF FW}

After starting the FW program, the first window shows the menu bar as in Table 2. Forest data can be read by selecting "Open" in the "File" menu. If the data format of the file being read is not identical to the sample data, the

Table 2 Command menu of FW

\begin{tabular}{lllll}
\hline File & Edit & Display & Project & Help \\
\hline Open & Copy & View & Magnification & About \\
Exit & & & Zoom in \\
& & & Zoom out \\
\hline
\end{tabular}

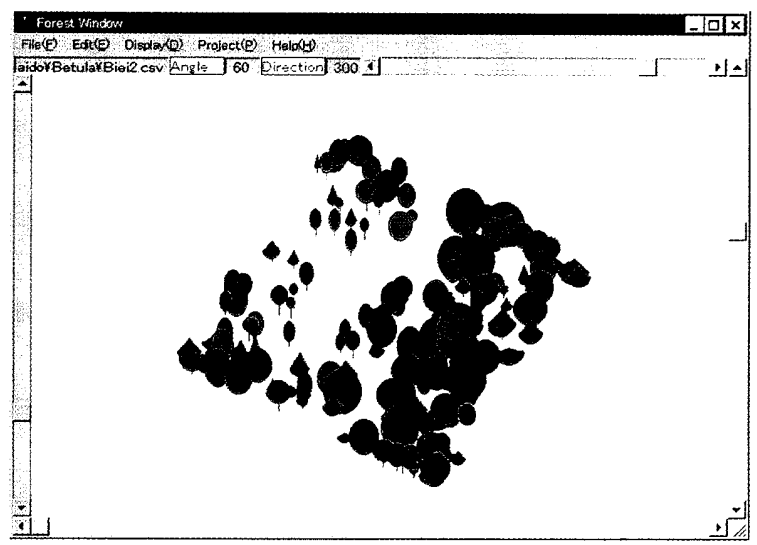

Fig.7 Forest structure after removing trees over 16meters in height

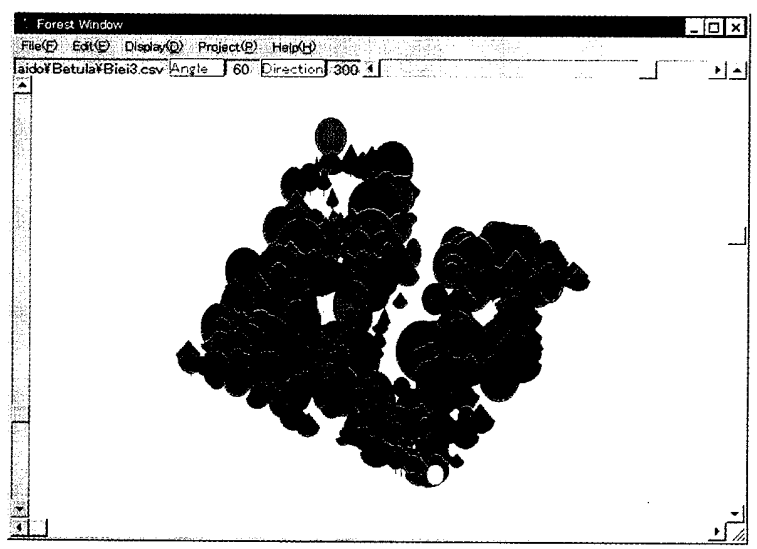

Fig.8 Forest structure after removing birches 
Table 3 Color code table

\begin{aligned} & \hline Code number Color name \\ & \hline 0 Black \\ & 1 Gray \\ & 2 Dark navy blue \\ & 3 Light navy blue \\ & 4 Dark red \\ & 5 Light red \\ & 6 Dark purple \\ & 7 Light purple \\ & 8 Dark green \\ & 9 Light green \\ & 10 Dark blue \\ & 11 Light blue \\ & 12 Dark yellow \\ & 13 Light yellow \\ & 14 Dark white \\ & 15 Light white \\ & \hline\end{aligned}

message: "The fields are different from FW data" is shown. During the file reading, FW shows the file name at the upper left side of the window. When "View" in the "Display" menu is selected, the forest structure will be displayed on the screen. The initial viewpoint is at a direction of 300 degrees and at an angle of 30 degrees. The viewpoint can be moved by the left-side and topside scroll bars. The left-side scroll bar is the angle controller and the topside scroll bar is the direction controller. Also, the angle and direction can be directly entered in a text window on the upper left side.

Zoom in and out of forest view can be selected on the "project" menu. Zoom in and out can be done in steps of 20 percent, and can be repeated any number of times. The forest stand structure displayed can be copied to the clipboard to use in other applications by selecting "Copy" in the "Edit" menu. These pictures are drawn a Windows metafile, so the pictures can be edited on almost all image processors.

FW can show a forest of about one hectare area with 40 meter maximum tree height. The origin of the coordinate axes is the center of the window. The forest data can be edited using a spreadsheet. If the forest area is less than one hectare, the forest structure can be zoomed up.

Tree crowns can be displayed in 16 different colors. The color codes are set out in Table 3 . Crown color is determined by the $\mathrm{CC}$ field numeric codes. The color codes can be related to tree species, diameter class, height class or any other characteristic. The color code can be readily calculated in the spreadsheet. FW and a spreadsheet can be run simultaneously in MS-windows 95. The spreadsheet handles input and editing of forest tree data, and FW handles the display of the $3 \mathrm{D}$-image.

\section{ANALYSIS OF FOREST STAND STRUCTURE}

Fig. 4 shows an example of a one hectare stand of mixed forest in Hokkaido. The observation point is at a direction of 300 degrees and at an angle of 60 degrees. Tree crowns are displayed in 16 colors according to tree species. Birch is painted in light purple, oak is light red, fir is light green etc. The tree crowns cover the greater part of the ground. A trail can be seen through the center of the stand.

Fig. 5 shows the same forest at an angle of 30 degrees. The tree form can be seen better in this figure because of the lower angle. Fig. 6 shows the same forest at the horizontal level. This figure shows a vertical section of forest from which the height class of the trees can be seen. Fig. 7 shows a hypothetical case in which trees over 16 meters in height have been removed. Fig. 8 shows an example of the changed structure after thinning the birch species. After the thinning many oak and fir trees remain, and there are some open spaces.

These thinning operations are created by a spreadsheet application so FW can show any thinning models that can be stored in CSV format.

\section{DISCUSSION}

The old type of 3D-image viewer that was reported by authors in the past (NoBORI 1990) used 8-direction tree data because of the limited speed of computer graphic displays. FW uses a simpler format for forest data and can sort the tree data rapidly. FW and a spreadsheet can be run together. The old 3D-image viewer can view the forest from the sun's position, but FW can view from any position. Hence the forest data does not need to be surveyed on the north, south, east and west cardinal points. If the axes of coordinates are fixed to the north, south, east and west cardinal points and the view-point is set on the sun's position, FW shows where solar radiation strikes the forest cover.

The old 3D-image viewer could simulate thinning of the stand in the application software. In using FW, spreadsheet software handles the input and editing of forest tree data, and FW handles the display of the 3D-image. In conclusion, it can be seen that Forest Window, used in conjunction with a spreadsheet, can provide an effective and flexible way of studying forest stand structures and the effect of different thinning strategies. Forest images can be copied from $\mathrm{FW}$ and used in other image processing software.

\section{LITERATURE CITED}

FuJitsu, (1997a): F-Basic97 instruction manual. 332pp

FuJITSU, (1997b): F-Basic97 command manual. 520pp 
MicrosofT, (1997): Microsoft Office 97 for Windows instruction manual. $704 \mathrm{pp}$

MitcheLL, K. J., (1975): Dynamics and simulated yield of Douglas-fir. Forest Science Monograph 17: 1-39pp

NoвоRI, Y., (1990): The three-dimensional display of two forest stand structures using computer graphics. J. Jpn. For. Soc. 72: 234-238

NoвоRI, Y., (1991): Simulation of a natural forest in central Hokkaido by three-dimensional computer analysis. Proc. Symp. Integrated Forest Management Info. Sys.: 95-101
Nobori, Y., Hayashi, K., Kumagal, H., Kojima, S., Lepage, B.A. and SwEDA, T., (1997): Reconstruction of a tertiary fossil forest from the Canadian high Arctic using three-dimensional computer graphics. J. For. Plann. 3: 49-54

TANAKA, Y., (1944): Das urwaldswesen in Nord-Karafuto und Seine wirtshaftliche bedeutung. Research Bulletins of College Experiment Forests, Faculty of Agriculture, Kyusyu University, 14: 1-142

(Received 9 March 1998)

(Accepted 25 May 1998) 